\title{
Correction to: Cerebrovascular Disorders
}

\section{Fawaz Al-Mufti and Krishna Amuluru}

\section{Correction to:}

Fawaz Al-Mufti and Krishna Amuluru (eds.), Cerebrovascular Disorders, Neuromethods, vol. 170, https://doi.org/10.1007/978-1-0716-1530-0

The original version of this book was inadvertently published with incorrect affiliation for one of the volume editors. The affiliation has been updated in the book as follows:

Fawaz Al-Mufti, MD

Associate Chair of Neurology for Research, New York Medical College, Associate Professor of Neurology, Neurosurgery and Radiology, New York Medical College, Director of the Neuroendovascular Surgery Fellowship,

Neuroendovascular Surgery (Interventional Neurologist) Attending Medical Director of Neurocritical Care, Westchester Medical Center at New York Medical College,

Valhalla, NY, USA

The updated online version of this book can be found at https://doi.org/10.1007/978-1-0716-1530-0

https://doi.org/10.1007/978-1-0716-1530-0_1

https://doi.org/10.1007/978-1-0716-1530-0_6

https://doi.org/10.1007/978-1-0716-1530-0_18

https://doi.org/10.1007/978-1-0716-1530-0_19 